\title{
Hemodynamic Changes in Uterine Artery during Pyometra in Bitches
}

\author{
Prasanna Pati", P.C. Mishra, B.K. Patra and Basanti Jena \\ Department of ARGO, College of Veterinary Science and A.H., \\ OUAT, Bhubaneswar, 751003, India \\ *Corresponding author
}

\section{A B S T R A C T}

\section{Keywords}

Pyometra, Uterine artery,

Hemodynamic,

Ultrasound,

Dioestrus, Bitch

\section{Article Info}

Accepted:

04 April 2019

Available Online:

10 May 2019
Canine pyometra is a common disease in bitches, middle-aged to old and dioestrous bitches are frequently affected. In the present study bitches suffering from pyometra show significantly higher resistance Doppler waveform of uterine arteries as compared to cystic endometrial hyperplasia (CEH) and normal dioestrus bitches. In case of dioestrus and CEH groups showed lower blood flow velocities when compared to pyometra groups. Conversely dioestrus and $\mathrm{CEH}$ groups show higher hemodynamic indices in comparison to pyometra groups. Hemodynamic changes in the uterine artery in non pregnant (Control), Cystic endometrial Hyperplasia $(\mathrm{CEH})$ and pyometric bitches are measured. The mean values of PI of NP, CEH and Pyometric bitches have been recorded as $1.296 \pm 0.017$, $1.277 \pm 0.014$ and $1.15 \pm 0.013$ respectively. The mean values of RI of NP, CEH and pyometric bitches have been recorded as $0.634 \pm 0.027,0.472 \pm 0.012$ and $0.246 \pm 0.016$. The mean values of PSV and EDV of NP, CEH and pyometric bitches has been recorded as $6.140 \pm 1.161,46.197 \pm 2.503,69.006 \pm 0.473$ and EDV with $1.819 \pm 0.262,8.814 \pm$ $0.179,27.570 \pm 0.452$ respectively. It was concluded that there is significant difference in the hemodynamic parameters of uterine artery between nonpregnant, $\mathrm{CEH}$ and pyometric bitches.

\section{Introduction}

Two dimensional B-mode ultrasonography, augmented with colour doppler and Spectral doppler (Triplex doppler), have been used clinically for obstetrics and gynecology in various animal species. Triplex doppler allows quantitative and qualitative assessment of blood flow and helps in examination of blood velocity, blood direction and blood type to be obtained in real time. The cystic endometrial hyperplasia-pyometra complex (CEH-P) is one of the most prevalent uterine diseases in the female dog. Middle aged to old, diestrous bitches are frequently affected. Cystic endometrial hyperplasia is a subclinical disease characterized by the proliferation of endometrial glands resulting in the formation of fluid-filled cysts and luminal uterine contents which may be present (Batista et al., 2016).

Ultrasonographic characteristics of pyometra vary depending upon the extent of involvement and nature of content. Extensive involvement depicts round hypoechoic to anechoic areas placed side by side covering the complete abdomen while moderate 
involvement exhibits hypoechoic, roughly round structure ventral to ventro-lateral to the anechoic urinary bladder in transverse section. Mild involvement is more readily visualised on longitudinal section as mixed anechoic to hypoechoic tubular structure (Pande et al., 2006 and Singh et al., 2010). Doppler ultrasonography is a noninvasive technique that provides information about the organs perfusion. In bitches, this technique has been used to evaluate uterine arteries blood flow during oestrus, normal and abnormal pregnancy, and puerperium. Although the characterization of uterine blood flow by doppler ultrasound will probably contribute to the precocious diagnosis of $\mathrm{CEH}$ and pyometra, this technique has not been studied in bitches with uterine diseases so far. Thus, the aim of this study is to describe and compare uterine blood flow in normal diestrous bitches and others suffering from $\mathrm{CEH}$ and CEH-P complex.

\section{Materials and Methods}

Total fifty (50) number of bitches were screened, among them ten (10) pyometric, ten (10) were cystic endometrial hyperplasia (CEH) cases and ten (10) non pregnant bitches were taken as control. A real time, doppler ultrasonograohy machine (ALOKA PROSOUND ALPHA 6) with a multi frequency (3 to $11 \mathrm{MHz}$ ) micro convex probe was used for monitoring the uterus and ovary trans-abdominally. Two-dimensional ultrasonography in combination with colourdoppler and PW doppler was performed.

Ultrasonic evaluation of pyometra vary depending upon the extent of involvement of uterus and nature of the content. Mostly depicted by round hypoechoic to anechoic areas placed side by side ventral to ventrolateral to urinary bladder. Using B-mode ultrasound scanner with 3-11 $\mathrm{MHz}$ convex transducer ultrasonograms were evaluated for information of size, shape, contour and internal architecture including alteration in echogenicity and intensity (anechoic/ hypoechoic/hyperechoic pattern). Colour doppler ultrasonography was performed to characterize uterine blood flow in pyometric cases. Doppler velocimetric evaluation allow for the differential diagnosis between $\mathrm{CEH}$, mucometra, endometritis and pyometra, whenever clinical symptoms and ultrasonographic findings are inconclusive.

\section{Results and Discussion}

\section{Ultrasonographic measurements}

Two dimensional ultrasonographic evaluations of the uterus was carried out by using (3 -11 MHz) convex probe. The widest cross sectional area of the uterus was taken. Then colour doppler was conducted to localize uterine arteries at both sides of the uterine body and pulse wave Doppler was performed to obtain the waveform. The angle of insonation was adjusted manually and measurements with an angle less than $30^{\circ}$ were only considered for analysis. Three consecutive waveforms with maximum Doppler shift included in the study. Peak systolic Velocity (PSV; $\mathrm{cm} / \mathrm{s}$ ), End diastolic Velocity (EDV; $\mathrm{cm} / \mathrm{s}), \mathrm{RI}$ and PI were measured automatically.

Hemodynamic changes in the uterine artery in Non pregnant (Control), Cystic endometrial Hyperplasia (CEH) and pyometric bitches are presented in the Table 1 . The mean values of PI of NP, CEH and Pyometric bitches has been recorded as $1.296 \pm 0.017,1.277 \pm 0.014$ and $1.15 \pm 0.013$ respectively. PI values of NP bitches ranges between $1.21-1.37, \mathrm{CEH}$ $1.20-1.33$ and incase of pyometra between $1.11-1.24$. There is significant difference in the PI values between NP and pyometric bitches bearing superscript $b$ and no significant difference in PI values between 
$\mathrm{NP}$ and $\mathrm{CEH}$ affected bitches at $(\mathrm{P}<0.01$ level).

The mean values of RI of NP, CEH and pyometric bitches has been recorded as 0.634 $\pm 0.027,0.472 \pm 0.012$ and $0.246 \pm 0.016$ presented in the Table 1 . RI values of NP bitches ranges from $0.42-0.72$, in CEH cases $0.41-0.53$ and in pyometric bitches between $0.20-0.33$. There is significant difference in the RI values between these three groups bearing superscript a,b,c at $(\mathrm{P}<0.01$ level).

The mean values of PSV and EDV of NP, $\mathrm{CEH}$ and pyometric bitches has been recorded as $6.140 \pm 1.161,46.197 \pm 2.503,69.006 \pm$ 0.473 and EDV with $1.819 \pm 0.262,8.814 \pm$ $0.179,27.570 \pm 0.452$ respectively. PSV values of NP bitches ranges between $2.70-$ $11.99 \mathrm{~cm} / \mathrm{s}$, CEH cases $38.14-58.67 \mathrm{~cm} / \mathrm{s}$ and in pyometric bitches $67.30-72.12 \mathrm{~cm} / \mathrm{s}$. Similarly EDV values of NP bitches ranges between $0.87-3.28 \mathrm{~cm} / \mathrm{s}$, CEH cases 8.34 $9.92 \mathrm{~cm} / \mathrm{s}$ and in pyometric bitches $25.43-$ $29.56 \mathrm{~cm} / \mathrm{s}$. Statistical analysis as revealed from Table 1 indicated there is high significant difference $(\mathrm{P}<0.01)$ level in the PSV and EDV values of Non pregnant, CEH and pyometric bitches.

Table.1 Haemodynamic changes in uterine artery in non- pregnant, ceh (Cystic Endometrial Hyperplasia) and pyometra cases in bitches

\begin{tabular}{|c|c|c|c|c|c|}
\hline GROUP & TOTAL NO. & PI & RI & PSV & EDV \\
\hline NP(DIOESTRUS) & 10 & $1.296^{\mathbf{a}} \pm 0.01$ & $0.634^{\mathbf{a}} \pm 0.02$ & $6.140^{\mathbf{a}} \pm 1.161$ & $1.819^{\mathbf{a}} \pm 0.262$ \\
\hline CEH & 10 & $1.277^{\mathbf{a}} \pm 0.01$ & $0.472^{\mathbf{b}} \pm 0.01$ & $46.197^{\mathbf{b}} \pm 2.50$ & $8.814^{\mathbf{b}} \pm 0.179$ \\
\hline PYOMETRA & 10 & $1.15^{\mathbf{b}} \pm 0.013$ & $0.246^{\mathbf{c}} \pm 0.016$ & $69.006^{\mathbf{c}} \pm 0.473$ & $27.570^{\mathbf{c}} \pm 0.452$ \\
\hline
\end{tabular}

\section{Graph.1}

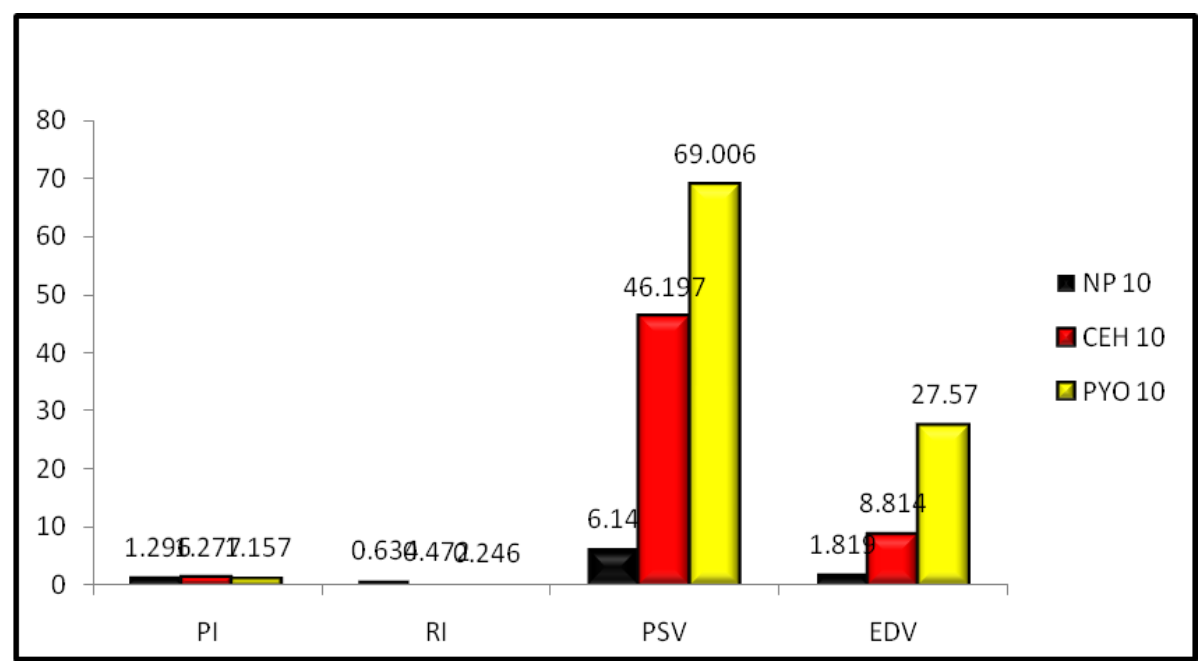

Pyometra in the bitch is considered to result from bacterial and hormonal interaction with hormonal factors playing a predisposing role (Arthur et al., 1996). There is usually an active infection with uropathogenic organisms and accumulation of fluid within the uterus during the progesterone-dominant phase of the estrus cycle. Some cases occur after the administration of steroid hormones for the control of breeding (Bowen et al., 1985). 
Classically the disease is associated with clinical signs such as polydipsia, polyuria, vaginal discharge, in appetence and lethargy (Feldman and Nelson, 1996).

Cystic endometrial hyperplasia is a subclinical disease characterized by the proliferation of endometrial glands resulting in the formation of fluid-filled cysts and luminal uterine contents may be present in some cases Schaffler and Gifford (2008). Pyometra, which is associated with purulent contents, presents severe systemic signs of illness because of the bacterial infection (Hagman et al., 2011). Conversely, when the uterine contents are serous, bloody, or mucoid, the condition is generally not associated with any clinical sign other than infertility. Sterile uterine fluids can be considered as the initiating stage that progresses into pyometra after uterine bacterial colonization occurs (Pretzer et al., 2008).In dogs, ultrasonographic evaluation of the uterus provides valuable information to diagnose uterine diseases.

Doppler ultrasonography is a noninvasive technique that provides information about the organs perfusion. This technique has found to be a useful tool to diagnose numerous gynecologic lesions in several species. Doppler ultrasound helps in the characterization of uterine blood flow that helps in the diagnosis of $\mathrm{CEH}$ and pyometra. Thus, the aim of this study was to describe and compare uterine blood flow in normal diestrous bitches and other suffering from $\mathrm{CEH}$ and CEH-P complex.

In the present study bitches suffering from pyometra shows significantly lower resistance Doppler waveform of uterine arteries as compared to cystic endometrial hyperplasia (CEH). RI values found in case of normal dioestrus and $\mathrm{CEH}$ bitches is higher than that of pyometric group bitches which is similar to as reported by (Batista et al., 2016) and lower than (Gal et al., 2012). In case of dioestrus and CEH groups (PSV: 6.140 \pm 1.161 ; EDV: $1,819 \pm 0.262$ and PSV: $46.197 \pm 2.503$; EDV: $8.814 \pm 0.179$ ) showed lower blood flow velocities when compared to pyometra groups (PSV: $69.006 \pm 0.473$; EDV: $27.570 \pm 0.452$ ). Conversly, dioestrus and $\mathrm{CEH}$ groups (RI: 0.634 \pm 0.027 ; PI: $1.296 \pm 0.017$ and RI: $0.472 \pm$ 0.012 ; PI: $1.277 \pm 0.014$ ) respectively shows higher hemodynamic indices in comparison to pyometra groups (RI: $0.246 \pm 0.016$; PI: 1.15 $\pm 0.013)$ similar to the findings of (Gal et al., 2012).

During inflammatory process, there is increased in blood flow, vasodialtion and angiogenesis are present. According to the scientist (Heap et al., 1975 and Still et al., 1978) increase in the intrauterine concentration of prostaglandin $\mathrm{E}$, which may lead to an increase in the uterine perfusion. In addition to prostaglandin, nitric oxide a potent vasodilator is also released locally in several mammalian species during endometrial inflammation in this study normal dioestrus/Control animal shows RI value below 0.75 , thus this threshold value could be used for differential diagnosis between Cystic endometrial Hyperplasia (CEH).

Doppler examination of uterine arterial flow during $\mathrm{CEH}$ and in pyometric bitches will improve the clinical outcome, avoids unnecessary surgery and preserve the reproductive tract in valuable bitches. Uterine artery blood flow of bitches suffering from pyometra was higher not only from normal bitches but also from females with endometrial hyperplasia. Doppler velocimetric evaluation helps in differential diagnosis of $\mathrm{CEH}$, endometritis and pyometra, whenever clinical symptoms and ultrasonographic findings are inconclusive, hence unnecessary treatment can be avoided. 


\section{References}

Arthur, G H., Noakes D E, Pearson H and Parkinson T J (1996). Cystic Endometrial Hyperplasia and Pyometra. In Veterinary Reproduction and Obstetrics. $7^{\text {th }}$ Edn. W B Saunders Company Ltd., London. pp. 527-544.

Batista, P R., Gobello C, Rube A Y, Corrada A, Tortora M and Blanco P G (2016). Uterine blood flow evaluation in bitches suffering from cystic endometrial hyperplasia $(\mathrm{CEH})$ and CEH-pyometra complex. Theriogenology 85 1258-1261.

Bowen, RA., Olson $\mathrm{P}$ N, Behrendt $\mathrm{M}$ D, Wheeler S L, Husted P W and Net T $M$ (1985). Efficacy and toxicity of estrogens commonly used to terminate canine pregnancy. Journal of American Veterinary Medical Association, 186: 783-788.

Feldman, E.C., and Nelson R W (1996) .Cystic Endometrial Hyperplasia and Pyometra Complex. Canine and Feline Endocrinology and Reproduction. $2^{\text {nd }}$ Edn. pp. 605-618.

Gal, V., Angriman D S R, Szulczewiski C R, Celeghini E C C, Papa P C and Vannucchi C (2012). Uterine Doppler velocimetry in bitches with cystic endometrial hyperplasia-pyometra.7th International Symposium on Canine and Feline Reproduction ISCFR .

Hagman, R., Lagerstedt A S, Hedhammar A and Egenvall A (2011). A breedmatched case control study of potential risk-factors for canine pyometra. Theriogenology 75: 12511257.

Heap, R.B., and Poyster N.L. (1975). Prostaglandins in pyometrial fluid from the cow, bitch ad ferret. $\mathrm{Br} \mathrm{J}$ Pharmacol; 55: 515-8.

Pande, N., Prabhakar S, Gandotra V K, Honparkhe M and Nanda A S (2006). Efficacy of different techniques for diagnosis of pyometra in female dogs. Indian Journal of Animal Reproduction 27: 31-33.

Pretzer, S.D., (2008).Clinical presentation of canine pyometra and mucometra: A review. Theriogenology 70: 359-363.

Schlafer, D., and Gifford A (2008).Cystic endometrial hyperplasia, pseudoplacentational endometrial hyperplasia, and other cystic conditions of the canine and feline uterus. Theriogenology;70:349-58.

Singh, K.P., Singh B, Singh J P, Singh S V, Singh P and Singh H N (2010). Diagnostic and therapeutic management of pyometra in bitches. Intas Polivet 11: 86-87

Still, J.G., and Greiss J F (1978). The effect of prostaglandins and other vasoactive substances on uterine blood flow and myometrial activity. Am J Obstet Gynecol; 130: 1-8.

\section{How to cite this article:}

Prasanna Pati, P.C. Mishra, B.K. Patra and Basanti Jena. 2019. Hemodynamic Changes in Uterine Artery during Pyometra in Bitches. Int.J.Curr.Microbiol.App.Sci. 8(05): 381-385. doi: https://doi.org/10.20546/ijcmas.2019.805.045 